\title{
Bmi1 regulates auditory hair cell survival by maintaining redox balance
}

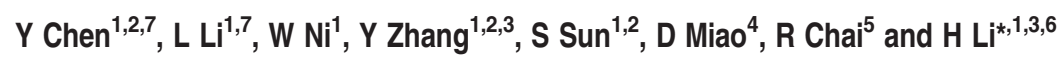

Reactive oxygen species (ROS) accumulation are involved in noise- and ototoxic drug-induced hair cell loss, which is the major cause of hearing loss. Bmi1 is a member of the Polycomb protein family and has been reported to regulate mitochondrial function and ROS level in thymocytes and neurons. In this study, we reported the expression of Bmi1 in mouse cochlea and investigated the role of Bmi1 in hair cell survival. Bmi1 expressed in hair cells and supporting cells in mouse cochlea. Bmi1 $1^{-l-}$ mice displayed severe hearing loss and patched outer hair cell loss from postnatal day 22. Ototoxic drug-induced hair cells loss dramatically increased in $\mathrm{Bmi}^{-I-}$ mice compared with that in wild-type controls both in vivo and in vitro, indicating Bmi1 ${ }^{-I-}$ hair cells were significantly more sensitive to ototoxic drug-induced damage. Cleaved caspase-3 and TUNEL staining demonstrated that apoptosis was involved in the increased hair cell loss of $\mathrm{Bmi1}^{-1-}$ mice. Aminophenyl fluorescein and MitoSOX Red staining showed the level of free radicals and mitochondrial ROS increased in $\mathrm{Bmi}^{-I-}$ hair cells due to the aggravated disequilibrium of antioxidant-prooxidant balance. Furthermore, the antioxidant $\mathrm{N}$-acetylcysteine rescued Bmi $1^{-I-}$ hair cells from neomycin injury both in vitro and in vivo, suggesting that ROS accumulation was mainly responsible for the increased aminoglycosides sensitivity in $\mathrm{Bmi} 1^{-I-}$ hair cells. Our findings demonstrate that Bmi1 has an important role in hair cell survival by controlling redox balance and ROS level, thus suggesting that Bmi1 may work as a new therapeutic target for the prevention of hair cell death.

Cell Death and Disease (2015) 6, e1605; doi:10.1038/cddis.2014.549; published online 22 January 2015

Hearing loss is one of the most common sensory disorders in humans. Hair cells in the inner ear have an essential role in converting mechanical sound movement to neural signals for hearing and balance. Previous studies have reported that several genes involved in the survival of hair cells, including Pou4f3 (Xiang et al. ${ }^{1}$ ), Barhl1 (Li et al. ${ }^{2}$ ), Gfi1 (Wallis et al. ${ }^{3}$ ), Rb1 (Sage et al. ${ }^{4}$ ), Tmprss3 (Fasquelle et al. ${ }^{5}$ ), Eya1 (Lozlowki et al. ${ }^{6}$ ) and AMPK. ${ }^{7}$ Deficiency of these genes in hair cells lead to the loss of hair cells via lack of neurotrophic factors, ${ }^{8}$ disorder of cell cycle ${ }^{4}$ and dysfunction of cellular energy production. ${ }^{7}$ Reactive oxygen species (ROS) have important roles in noise- and ototoxic drug-induced hair cell damage and hearing loss. ${ }^{9}$ ROS include less-reactive ROS and high ROS (hROS); high levels of both less-reactive ROS and hROS can oxidize cell constituents, including DNA, proteins and lipids and active multiple apoptosis pathways including mitogen-activated protein kinase, Fas-FasL, NF$\kappa \mathrm{B}$, DNA damage response (DDR) and p53 signaling pathways. ${ }^{10-13}$ ROS can also directly attack mitochondrion and lead to the release of cytochrome $c .^{14,15}$ Mitochondria are not only cellular organelles required for aerobic respiration but also the main source of intracellular ROS, which are thought to be the cause of most oxidative damage. Because of the abundant number of mitochondria and high consumption of oxygen, auditory hair cells are exposed to high level of oxidative stress, especially when challenged by ototoxic drugs. $^{9,16-19}$ The balance between prooxidant and antioxidant molecules is critical to determine the rate of oxidative damage accumulation. Administration of ROS-scavenging antioxidants, ${ }^{16,20-23}$ as well as inhibition of oxidase, ${ }^{18}$ can reduce the ROS production, thus attenuating the subsequent hair cell death in ototoxic drug-treated cochleae.

Bmi1 is a member of the Polycomb group (PcG) family. PcG proteins form large complexes, including PRC1 (Polycomb repressive complex 1 ) and PRC2 (Polycomb repressive complex 2), which silence target genes by modifying chromatin organization. ${ }^{24,25} \mathrm{Bmi} 1$ also can bind to the Run $x 1 / C B F \beta$ transcription factor complex to silence target gene in a PRC2-independent manner. ${ }^{26}$ Although many researchers focus on the role of Bmi1 in self-renewal of

\footnotetext{
${ }^{1}$ Department of Otorhinolaryngology, Hearing Research Institute, Affiliated Eye and ENT Hospital of Fudan University, Shanghai 200031, China; ${ }^{2}$ Central Laboratory, Affiliated Eye and ENT Hospital of Fudan University, Shanghai 200031, China; ${ }^{3}$ Institutes of Biomedical Sciences, Fudan University, Shanghai 200032, China; ${ }^{4}$ State Key Laboratory of Reproductive Medicine, Research Center for Bone and Stem Cells, Department of Human Anatomy, Nanjing Medical University, Nanjing 210096, China; ${ }^{5}$ Co-innovation Center of Neuroregeneration, Key Laboratory for Developmental Genes and Human Disease, Ministry of Education, Institute of Life Sciences, Southeast University, Nanjing 210096, China and ${ }^{6}$ State Key Laboratory of Medical Neurobiology, Fudan University, Shanghai, China

*Corresponding author: $\mathrm{H} \mathrm{Li}$, Department of Otorhinolaryngology, Hearing Research Institute, Affiliated Eye and ENT Hospital of Fudan University, Shanghai 200031, China. Tel: +86 02164377134 669; Fax: +86 21 64377151; E-mail: hwli@shmu.edu.cn

${ }^{7}$ These authors contributed equally to this work.

Abbreviations: ROS, reactive oxygen species; APF, aminophenyl fluorescein; NAC, N-acetylcysteine; DDR, DNA damage response; PRC, Polycomb repressive complex; ABR, auditory brain stem response; DPOAE, distortion product otoacoustic emission; Alox15, arachidonate 15-lipoxygenase; Cdo1, cysteine dioxygenase 1; Lpo, lactoperoxidase; Duox2, dual oxidase 2; xCT, also known as SIc7a11, solute carrier family 7, member 11; Nq01, NAD(P)H dehydrogenase, quinone 1; Sod1, superoxide dismutase 1, soluble; Sod2, superoxide dismutase 2, mitochondrial; Gsr, glutathione reductase; Gstm1, glutathione S-transferase, mu 1; Noxa, also known as Pmaip1, phorbol-12-myristate-13-acetate-induced protein 1; Puma, also known as Bbc3, BCL2-binding component 3

Received 01.9.14; revised 13.11.14; accepted 17.11.14; Edited by J Chipuk
} 
embryonic, adult and cancer stem cell, ${ }^{27-36}$ several evidences suggest that Bmi1 also regulate cell survival by controlling mitochondrial function and ROS level. Previous report showed that Bmi1-deficient thymocytes have impaired mitochondrial function, which lead to a marked increase of intracellular ROS levels and subsequent engagement of the DDR pathway. ${ }^{13}$ In Bmi1-deficient CD34(+) stem cells, the reduced ability of self-renewal is associated with enhanced apoptosis, which coincided with increased levels of intracellular ROS. ${ }^{37}$ Bmi1 controls memory CD4 T-cell survival through direct repression of Noxa gene in an Ink4a- and Arf-independent manner. ${ }^{38}$ Overexpression of Bmi1 in vivo protects human embryonic stem cells (HSCs) from ROS damage and extends the lifespan of $\mathrm{HSCs},{ }^{39}$ whereas Bmi1 transduction in vitro reduced irradiation-induced ROS levels by suppressing the oxidase genes, including lactoperoxidase (Lpo), and increased repair of DNA damage in human keratinocytes. $^{40}$

Bmi1 also expressed in terminally differentiated cells, such as neurons, ${ }^{41}$ besides stem cells and rapidly dividing cells. It is reported that Bmi1 is required in neurons to suppress p53induced apoptosis via regulating the antioxidant defensive response. $^{42}$ High Bmi1 expression level in cortical neurons resulted in the suppression of ROS through activation of antioxidant genes and conferred robust protection against DNA-damage-induced cell death or mitochondrial poisoning. ${ }^{41}$

However, the expression of Bmi1 and its function in the inner ear have not been reported. In this study, we investigated Bmi1 expression in mouse cochlea and its role in hair cell survival. We found that Bmi1 is expressed in the hair cells and supporting cells, and can regulate the redox balance and ROS levels, thus having an important role in the survival and sensitivity to ototoxic drug of auditory hair cells in mice cochleae.

\section{Results}

Bmi1 expressed in auditory hair cells. To investigate the Bmi1 expression in mouse cochlea, we used immunofluorescence staining with anti-Bmi1 antibody (Millipore, Consett, UK). Myosin 7a and sex-determining region $\mathrm{Y}$ )-box 2 (Sox2) were used as hair cell and supporting cell markers, respectively. Bmi1 expressed in both hair cells and supporting cells in the cochlea of neonatal and P30 wild-type (WT) mice (Figures 1a and b). Bmi1 also expressed in spiral ligament and spiral ganglion cells (data not shown).

\section{$\mathrm{Bmi1}^{-1-}$ mice showed severe hearing loss and auditory} hair cell loss. Taking advantage of Bmi1 knockout (KO) $\left(B m i 1^{-l-}\right)$ mice, we investigated the role of Bmi1 in cochlear hair cells. Immunofluorescence and PCR results confirmed that Bmi1 did not express in the cochlea of $\mathrm{Bmi}^{-1-}$ mice (Figures 1a and c). Auditory brain stem response (ABR) measurement revealed that hearing threshold at 8, 16, 24 and $32 \mathrm{KHz}$ significantly increased in postnatal day 22 (P22) and postnatal day 30 (P30) Bmi1 ${ }^{-1-}$ mice compared with WT littermate (Figure 2d) $(n=6, P<0.05)$, indicating severe hearing loss in $B \mathrm{mi}^{-1-}$ mice. Distortion product otoacoustic emission (DPOAE) measurement showed that hearing threshold at $8,12,16,20,24,28$ and $32 \mathrm{KHz}$ significantly increased in P30 Bmi1 ${ }^{-1-}$ mice compared with WT littermate (Figure 2e) ( $n=6, P<0.05$ ), suggesting that $B$ mi1 is important to hearing function. The hearing threshold of $\mathrm{Bmi}^{+/}$mice showed no significant differences when compared with WT controls.

Morphological study showed there was no obvious change of cochlea structure at all three turns in the neonatal $\mathrm{Bmi}^{-1-}$ mice. The number and morphology of hair cells in neonatal $\mathrm{Bmi1}^{-/-}$mice is similar to that in WT littermate (Figure 2a), suggesting that Bmi1 does not affect the development of auditory hair cells. However, at P22, outer hair cell loss started a

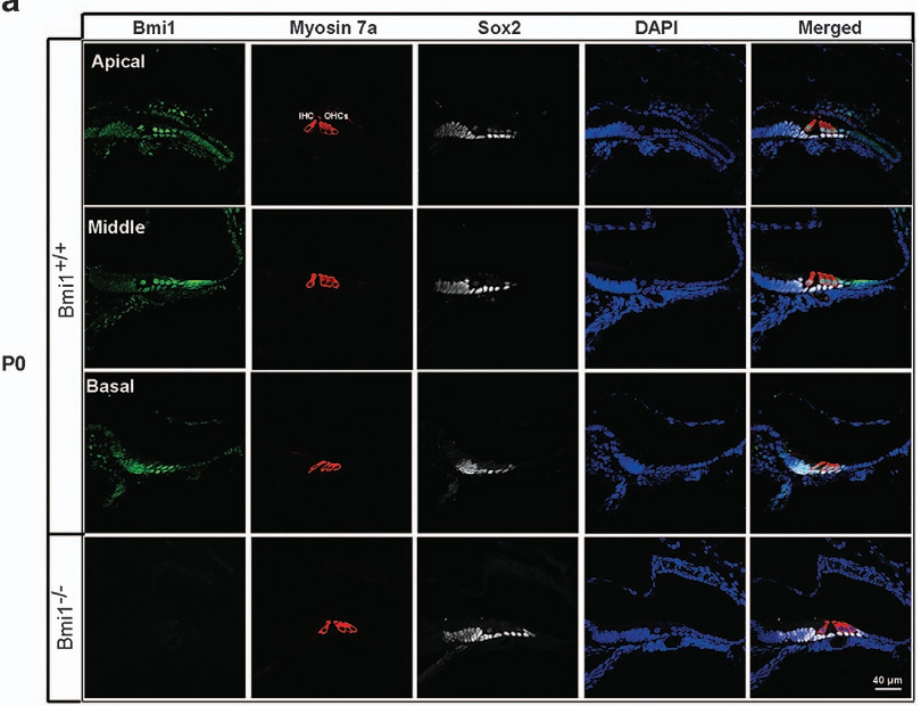

b

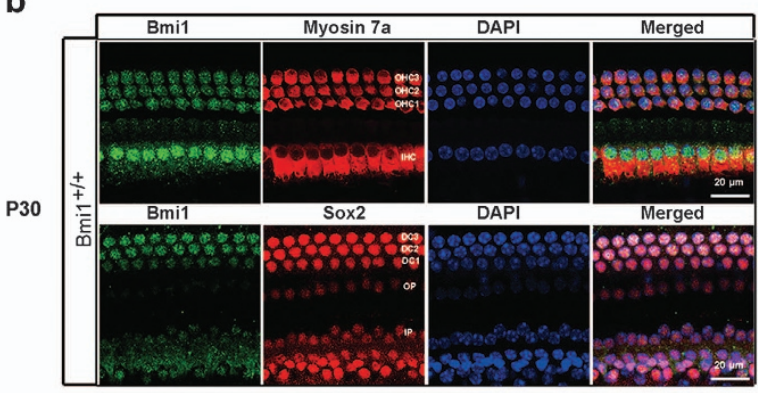

c

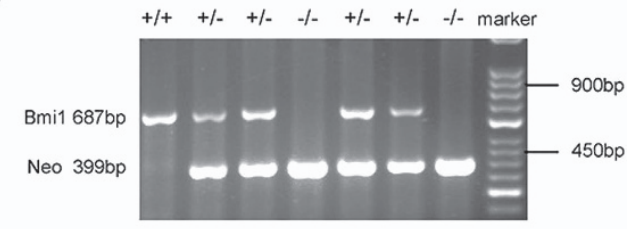

Figure 1 Bmi1 expressed in auditory hair cells and supporting cells. (a) Immunofluorescence staining showed Bmi1 expression in the apical, middle and basal turns in the Corti's organ of neonatal (P0) WT mice. Myosin 7a and Sox2 were used as hair cell and supporting cell markers, respectively. (b) Bmi1 expressed in the cochlear epithelium of P30 WT mice. (c) Typical PCR data of genotyping. Scale bars: $40 \mu \mathrm{m}$ (a); $20 \mu \mathrm{m}$ (b). OHC, outer hair cell; IHC, inner hair cell; DC, Deiters' cell; IP, inner pillar cell; OP, outer pillar cell 
a

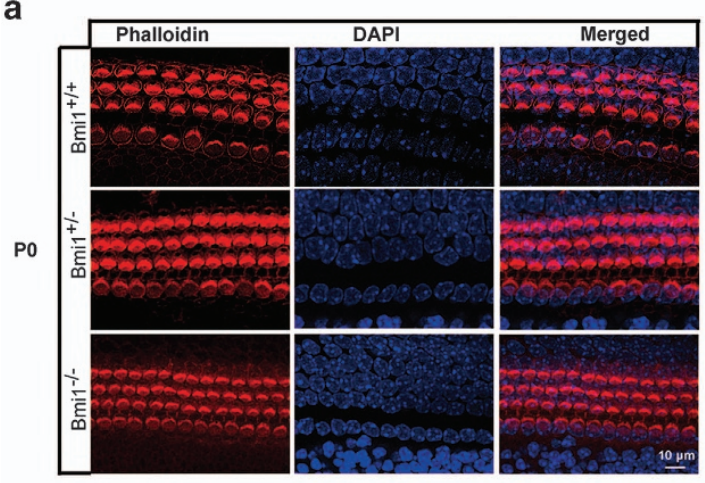

b

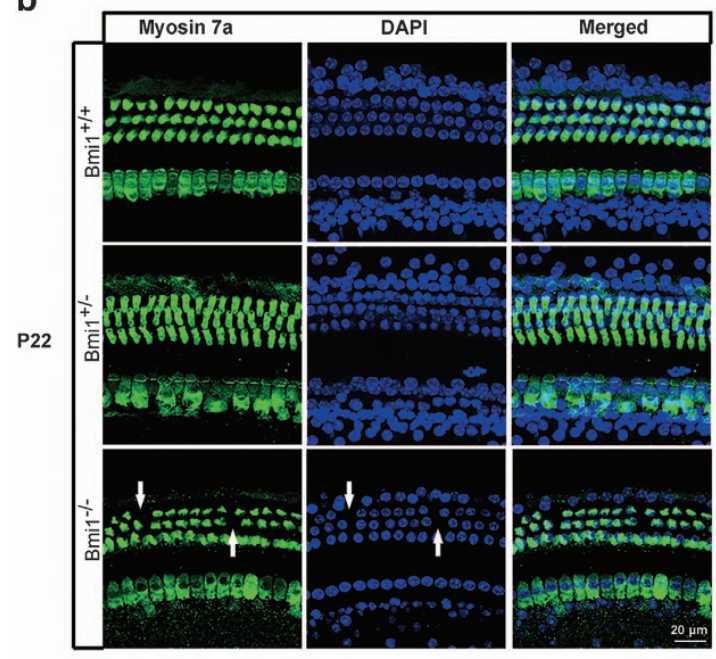

c
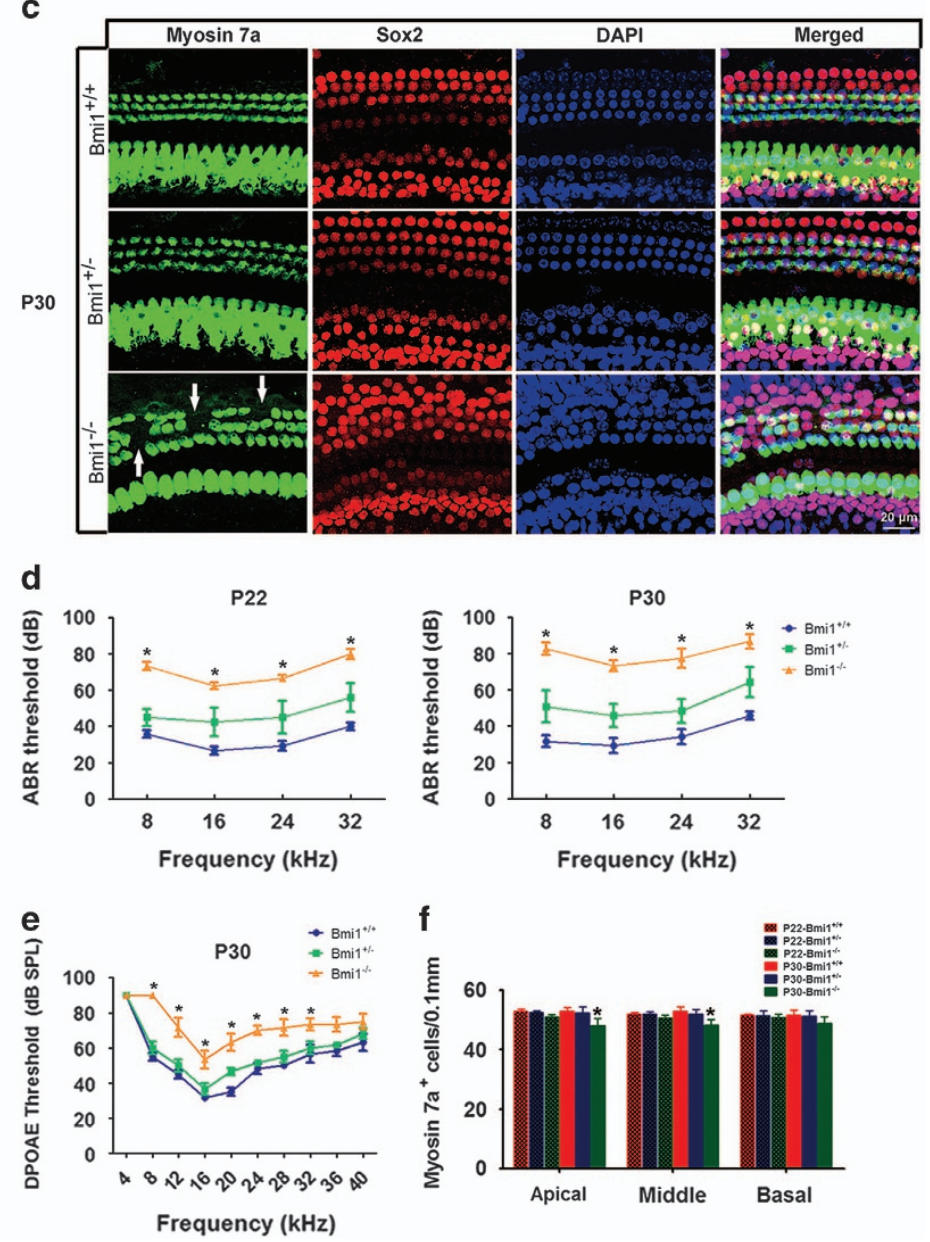

Figure $2 \mathrm{Bmi1}^{-1-}$ mice showed severe hearing loss and patched auditory hair cell loss. (a) Phalloidin staining showed that the number and morphology of cochlear hair cells are

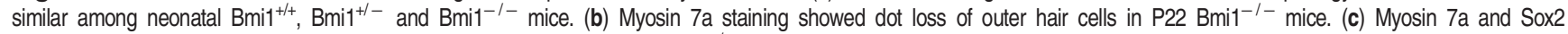
immunofluorescence staining showed patched loss of outer hair cells in P30 Bmi1 ${ }^{-1-}$ mice. (d) ABR measurement revealed that hearing threshold at 8, 16, 24 and $32 \mathrm{KHz}$ significantly increased in Bmi1 ${ }^{-1-}$ mice compared with WT littermate at P22 and P30. (e) DPOAE measurement showed the function of outer hair cells was impaired in P30 Bmi $1^{-1-}$ mice. (f) Statistical data of myosin 7a positive cells in the cochlea of P22 and P30 mice. Scale bars: $10 \mu \mathrm{m}(\mathbf{a}) ; 20 \mu \mathrm{m}$ (b and $\mathbf{c}){ }^{*} P<0.05$ versus Bmi ${ }^{+/+}$group. $n=6$ for each group

to appear in the apical and middle turns of $\mathrm{Bmi1}^{-/-}$mice (Figure 2b). More outer hair cell loss has been observed in all three turns at P30 (Figure 2c). Although supporting cells in $\mathrm{Bmi}^{-/-}$mice were also disorganized at P30, the number of supporting cells showed no significant difference among $\mathrm{Bmi1}^{-/-}, \mathrm{Bmi}^{+/-}$and WT mice (Figure 2c).

Hair cells of $\mathrm{Bmi1}^{-/-}$mice were more vulnerable to ototoxic drug-induced ototoxicity. To investigate the role of Bmi1 in hair cell survival, first the cochlea of $\mathrm{PO} \mathrm{Bmi1}{ }^{-1-}$, $\mathrm{Bmi}^{+/-}$and WT mice were cultured and treated with $0.25 \mathrm{mM}$ neomycin for $24 \mathrm{~h}$ in vitro. In the absence of damage, hair cells in the cultured cochlea were indistinguishable between $\mathrm{Bmi1}^{-/-}, \mathrm{Bmi}^{+/-}$and WT mice (Figure 3a). After treatment with $0.25 \mathrm{mM}$ neomycin for $24 \mathrm{~h}$, hair cell loss in the apical, middle and basal turns of WT mice were $1.45 \pm 2.89 \%$, $39.50 \pm 2.66 \%$ and $83.43 \pm 1.15 \%$, respectively. Strikingly, in $\mathrm{Bmi}^{-1}$ mice, hair cell loss in the apical, middle and basal turns significantly increased to $6.73 \pm 3.64 \%, 73.51 \pm 4.49 \%$ and $93.39 \pm 1.16 \%$, respectively (Figure $3 a)(n=5, P<0.05)$. Again, hair cell loss in $\mathrm{Bmi}^{+/-}$mice showed no significant differences when compared with the WT controls. To further confirm this finding, we used another ototoxic drug, cisplatin, to investigate the injury sensitivity of $\mathrm{Bmi}^{-/-}$hair cells. Unlike neomycin, cisplatin injured both hair cells and supporting cells in cochlear epithelium. Hair cell loss induced by cisplatin has no significant difference among the apical, middle and basal turns. In WT mice, hair cell loss of middle turn was $49.09 \pm 2.88 \%$ after $10 \mu \mathrm{M}$ cisplatin treatment for $24 \mathrm{~h}$. Hair cell loss significantly increased to $82.95 \pm 3.02 \%$ in $B m i 1^{-1-}$ mice (Figure 3a) $(n=5$, $P<0.05)$. Furthermore, the increased injury sensitivity to aminoglycosides of $\mathrm{Bmi}^{-/-}$hair cells was also confirmed by in vivo study. Neomycin ( $125 \mathrm{mg} / \mathrm{kg} /$ day) was administrated to the P7 $\mathrm{Bmil}^{-/-}, \mathrm{Bmi1}^{+/-}$and WT mice for 5 days. Ten days after neomycin injection, hair cell loss in the apical, middle and basal turns of WT mice were $0.44 \pm 0.32 \%, 0.25 \pm 0.34 \%$ and $5.69 \pm 1.67 \%$, respectively, whereas in $\mathrm{Bmi1}^{-/-}$mice, these percentages significantly increased to $0.72 \pm 0.48 \%$, $11.05 \pm 0.66 \%$ and $43.09 \pm 4.04 \%$, respectively (Figure $3 b$ ) ( $n=5, P<0.05)$. All these results suggested that endogenous expression of Bmi1 has an important role in the injury sensitivity to ototoxic drugs and the survival of cochlear hair cells. 
a

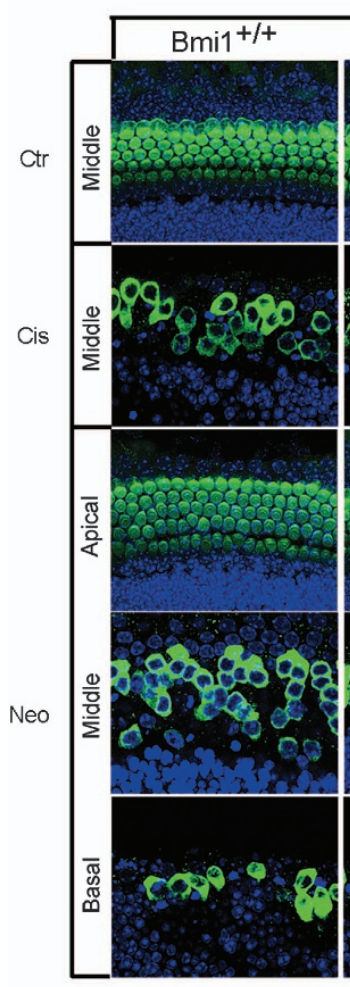

in vitro study

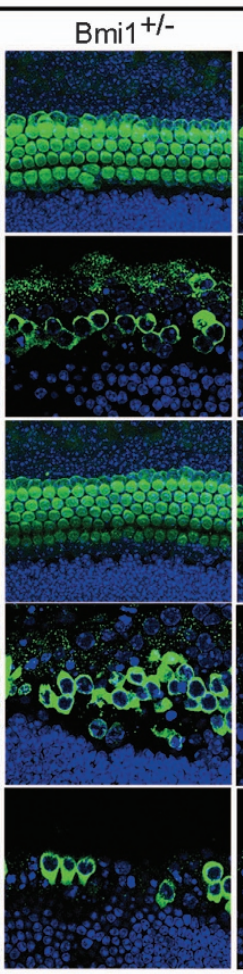

b

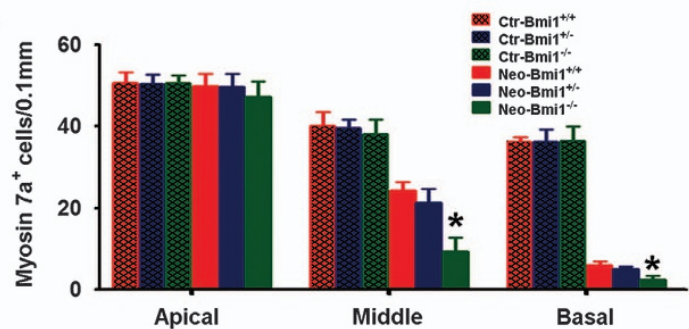

C

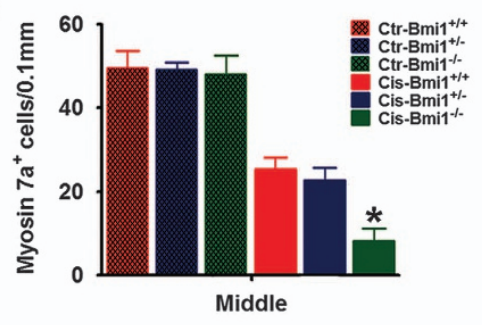

d

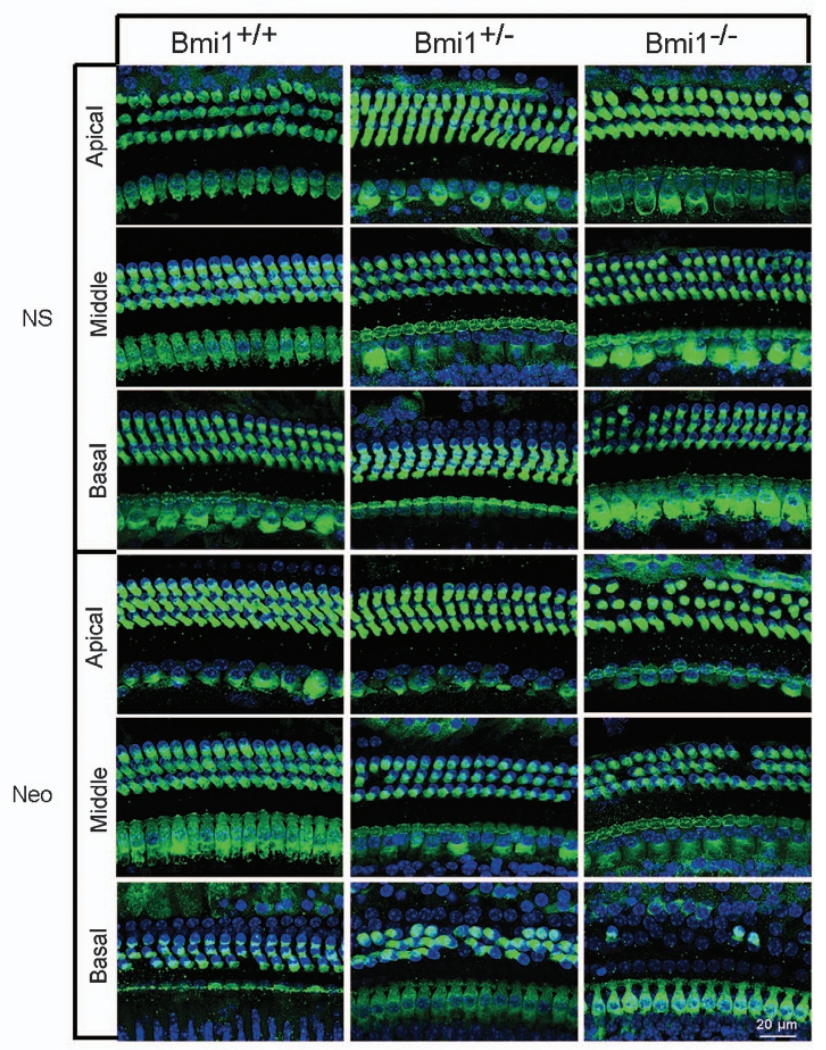

e

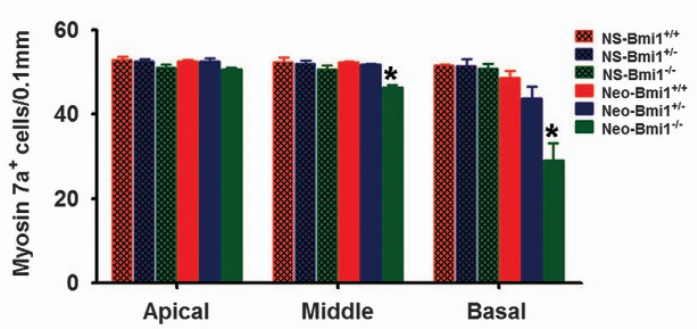

f

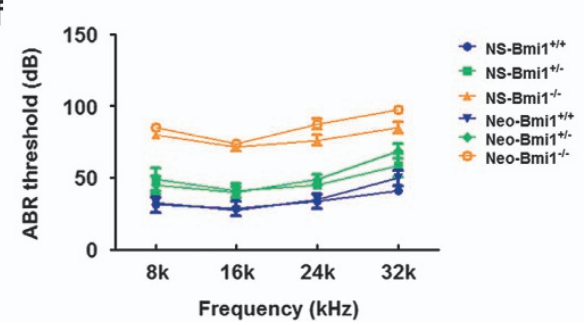

Figure 3 The sensitivity to ototoxic drugs increased in Bmi $1^{-1-}$ auditory hair cells. (a) In the absence of damage, myosin 7a immunostaining showed that hair cells in

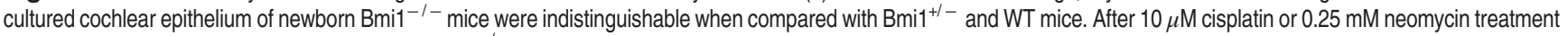
for $24 \mathrm{~h}$, hair cell loss significantly increased in Bmi $1^{-1-}$ cultured cochlear epithelium. Statistical data of myosin 7a-positive cells after neomycin (b) or cisplatin (c) treatment. (d) After treatment with neomycin (125 mg/kg/day for 5 days from P7), hair cell loss increased in Bmi $1^{-1-}$ mice compared with that in Bmi1 $1^{+/-}$and Bmi ${ }^{+/+}$mice. (e) Statistical data showed that neomycin-induced cochlear hair cell loss significantly increased in Bmi1 ${ }^{-1}$ mice compared with control littermates. (f) Hearing threshold evaluated by ABR measurement of Bmi1 ${ }^{-/-}, \mathrm{Bmil}^{+/-}$and Bmi1 ${ }^{+/+}$mice after neomycin treatment. Scale bars: $20 \mu \mathrm{m} .{ }^{*} P<0.05$ versus Neo-Bmi1 ${ }^{+/+}$group in $\mathbf{b}$ and $\mathbf{e}$, or Cis-Bmi1 ${ }^{+/+}$group in $\mathbf{c}$. $n=5$ for each group

\section{Apoptosis and DNA damage was involved in the increase} of ototoxic drug-induced hair cell loss in $\mathrm{Bmi1}^{-1-}$ cochlea. Previous studies revealed that apoptosis participate in the aminoglycoside-induced hair cell death. ${ }^{43}$ Cleaved caspase-3 and TUNEL could be used as markers of cell apoptosis. After neomycin treatment for $8 \mathrm{~h}$, the numbers of caspase-3-positive and myosin7a/caspase-3 double-positive cells were significantly increased in $\mathrm{Bmi}^{-1-}$ cochlea when compared with WT controls (Figure 4a). Increased apoptosis of $B \mathrm{mi}^{-/-}$hair cells when treated with aminoglycosides was 
further confirmed by a similar increase in the number of TUNEL/myosin7a double-positive cells in Bmi1 ${ }^{-1-}$ cochlear explants (Figure 4b).Quantitative RT-PCR and western blotting results showed that the expression of pro-apoptotic genes p53 and p53 target genes, including Noxa and Puma, significantly increased in $B \mathrm{mi}^{-1}$ - hair cells (Figures $4 \mathrm{e}$ and g). Taken together, these data indicated that apoptosis involved in the increase of aminoglycosides induced hair cell loss in $\mathrm{Bmi1}^{-/-}$mice.

$\gamma \mathrm{H} 2 \mathrm{AX}$ (phosphorylated $\mathrm{H} 2 \mathrm{AX}$ at the 139th serine residue), a sensitive indicator of DNA double-strand break, triggers Chk2 signaling pathway and p53 activation. ${ }^{44}$ After neomycin treatment, the level of $\mathrm{\gamma H} 2 \mathrm{AX}$ significantly increased in $\mathrm{Bmi}^{-1-}$ hair cells when compared with WT controls (Figure 4c), suggesting that DNA-damage-induced Chk2 signalling pathway might be involved in the increased sensitivity to aminoglycosides of $\mathrm{Bmi}^{-/-}$hair cells.

Free radicals and mitochondrial ROS levels increased in $\mathrm{Bmi1}^{-1-}$ hair cells after neomycin insult. It has been reported that aminoglycosides induced accumulation of hROS is closely related to hair cell damage. ${ }^{45}$ Aminophenyl fluorescein (APF), which is a green probe, can selectively detect hROS, including free hydroxyl radical $(\bullet \mathrm{OH})$, peroxynitrite (ONOO - ) and hypochlorite $(-\mathrm{OCl})$. In the absence of damage, APF fluorescence in cochlear epithelium could not be detected in both $\mathrm{Bmi}^{-1-}$ and WT mice (Figure 5a). Two hours after neomycin treatment, APF fluorescence could be detected in hair cells and the fluorescence intensity was significantly higher in $\mathrm{Bmi} 1^{-/}$mice than that in WT control (Figure 5a), indicating that hROS level significantly increased in $\mathrm{Bmi}^{-/-}$mice. Auditory hair cells possess many mitochondria and consume large amount of oxygen, and thus are sensitive to oxidative stress. MitoSOX Red, a redox fluorophore detecting selectively mitochondrial superoxide, ${ }^{13,46,47}$ were used to evaluate mitochondrial ROS generation in hair cells. In the absence of damage, no MitoSOX Red fluorescence was detected in both $\mathrm{Bmi}^{-1-}$ and WT epithelium (Figure 5b). Two hours after neomycin treatment, the fluorescence intensity of MitoSOX Red was significantly higher in $\mathrm{Bmil}^{-/-}$ mice than that in WT control (Figure 5b), indicating that mitochondrial ROS level significantly increased in $\mathrm{Bmi}^{-/-}$ mice. These results suggested that the increased levels of ROS might be the reason for the increased injury sensitivity to aminoglycosides of $\mathrm{Bmi}^{-/-}$hair cells.

The disequilibrium of antioxidant-prooxidant balance deteriorated in $\mathrm{Bmi1}^{-/-}$hair cells after neomycin injury. Cellular redox homeostasis depends on the antioxidantprooxidant balance. The increment of ROS levels in Bmi $1^{-/}$ hair cells might be caused by the decreased antioxidant levels and/or the increased prooxidant levels. Previous studies have reported the decreased expression levels of antioxidant genes ( $x C T$, Nqo1, Sod1 and Sod2) in Bmi1deficient neurons ${ }^{42}$ and the increased expression levels of oxidizing enzymes (Alox5, arachidonate 15-lipoxygenase (Alox15), Duox1, dual oxidase 2 (Duox2), cysteine dioxygenase 1 (Cdo1) and Lpo) in Bmi1-deficient thymocytes. ${ }^{13}$ To find out how Bmi1 deficiency leads to elevated ROS levels in $\mathrm{Bmi1}^{-/-}$cochlea, quantitative RT-PCR was used to investigate the expression levels of several antioxidant (xCT, Nqo1, Cat, Sod1, Sod2, Gsr and Gstm1) and prooxidant genes (Alox15, Lpo, Duox2 and Cdo1). In the absence of damage, the expression of both antioxidant and prooxidant genes showed no significant difference between $\mathrm{Bmi}^{-1-}$ and WT neonatal mice (Figures $5 \mathrm{~d}$ and e). Two hours after neomycin treatment, the expression levels of both antioxidant and prooxidant genes dramatically increased in the WT cochlea. However, the increment amplitude of prooxidant gene expression, including Alox15, Cdo1 and Lpo, increased significantly more in $\mathrm{Bmi}^{-1-}$ cochlea than in WT control (Figure 5d), whereas the increment amplitude of antioxidant gene expression, including xCT (also known as Slc7a11, solute carrier family 7, member 11), Nqo1 (NAD(P) $\mathrm{H}$ dehydrogenase, quinone 1 ) and superoxide dismutase 2 , mitochondrial (Sod2), increased significantly more in WT control than in $\mathrm{Bmi}^{-1-}$ cochlea (Figure 5e). These data demonstrated that the disequilibrium of antioxidant-prooxidant balance was aggravated in $\mathrm{Bmi1}^{-/-}$cochlear hair cells, which resulted in the much more severe ROS accumulation in $\mathrm{Bmi1}^{-1-}$ hair cells than in WT control.

Antioxidant treatment rescued the hair cells in $\mathrm{Bmi1}^{-I_{-}}$ cochlea. To further investigate whether the increment of ROS levels contribute to the increased injury sensitivity to aminoglycosides of $\mathrm{Bmi}^{-/-}$hair cells, the antioxidant $\mathrm{N}$ acetylcysteine (NAC), which is a reduced glutathione (GSH) provider and a direct scavenger of reactive oxygen intermediates, was used to treat the neomycin-injured hair cells. After NAC $(20 \mu \mathrm{M})$ treatment, hair cell loss dramatically decreased in both $\mathrm{Bmi}^{-1-}$ and WT control mice, and the number of survived hair cells has no significant difference between $\mathrm{Bmi1}^{-1-}$ and WT mice (Figures $6 \mathrm{a}$ and $\mathrm{c}$ ). The rescue effect of antioxidant treatment was further confirmed by in vivo study (Figures $6 b$ and $d$ ), demonstrating that ROS accumulation was the major cause of the high injury sensitivity of $\mathrm{Bmi1}^{-/-}$auditory hair cells to aminoglycosides.

\section{Discussion}

The Polycomb gene Bmi1 is extensively studied in stem cells and rapid dividing cells, such as cancer cells and lymphocytes. Although the role of Bmi1 in stem cell renewal has been largely understood, several evidences suggest that Bmi1 also regulates cell survival by controlling mitochondrial function and ROS level. However, the expression and function of Bmi1 in the cochlea remains unclear. In this study, we reported the expression of Bmi1 and demonstrated that Bmi1 regulates the survival of hair cells by controlling the accumulation of ROS in postnatal mice cochlea. We reported the severe hearing loss (Figure 2), the daily-increasing hair cell loss from P22 (Figure 2) and the increased susceptibility of hair cells to ototoxic drugs (Figure 3) in Bmi1 KO mice, which indicated that Bmi1 has an important role in regulating the survival of auditory hair cells. After neomycin treatment, we found loss of Bmi1 led to the significant increased accumulation of free radicals and mitochondrial ROS (Figure 5), which induced DNA damage and apoptosis of hair cell (Figure 4); and antioxidant treatment rescued this hair cell loss in Bmi1 KO cochlea (Figure 6). 


\section{a}

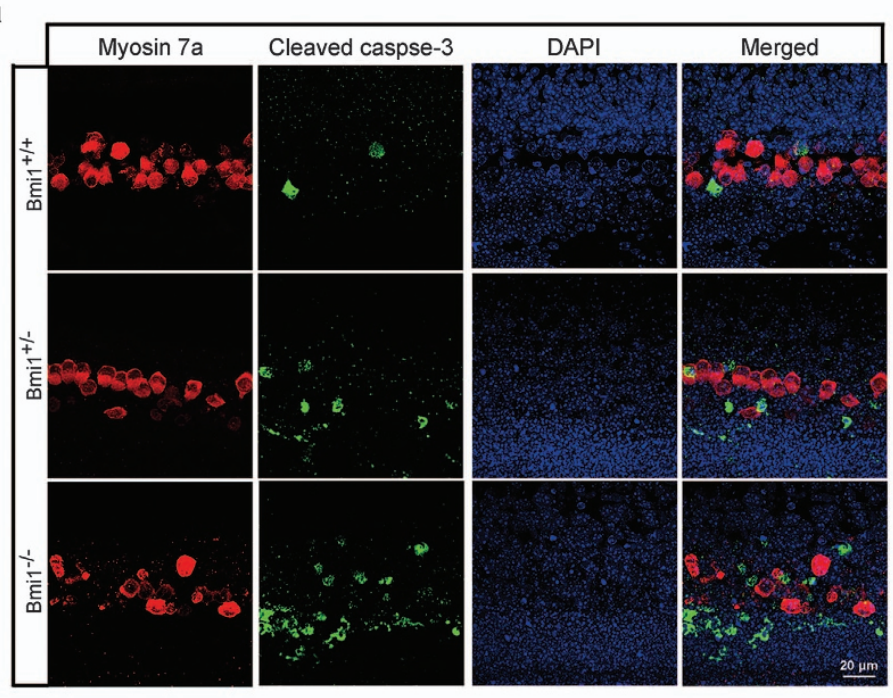

b

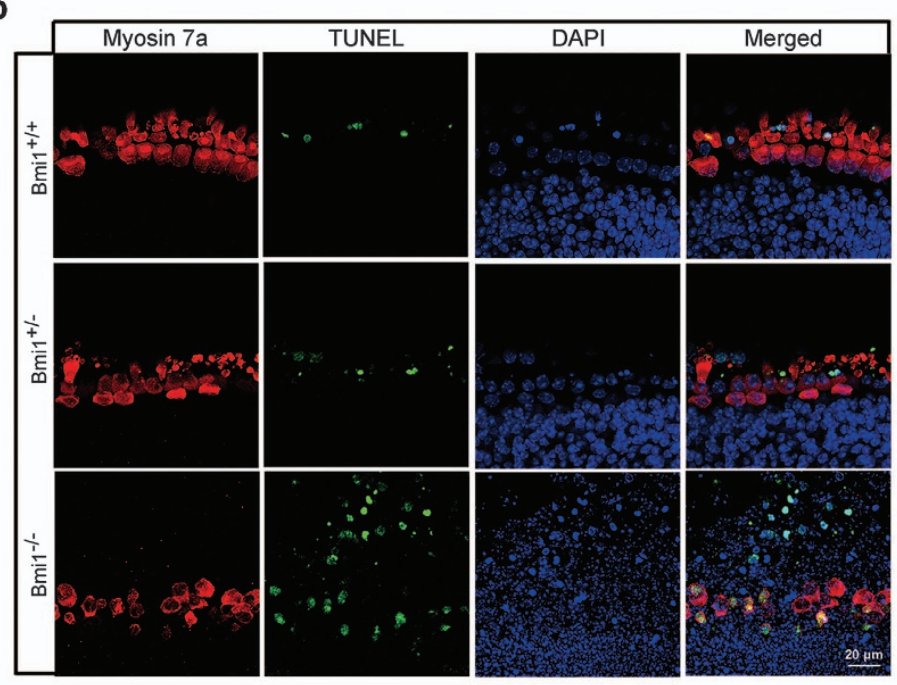

C

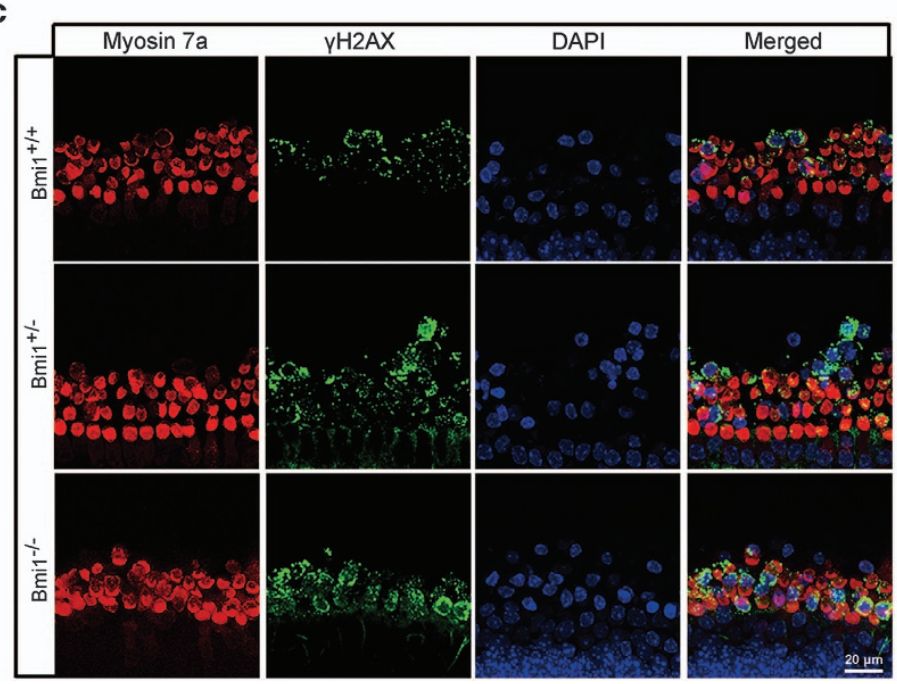

d
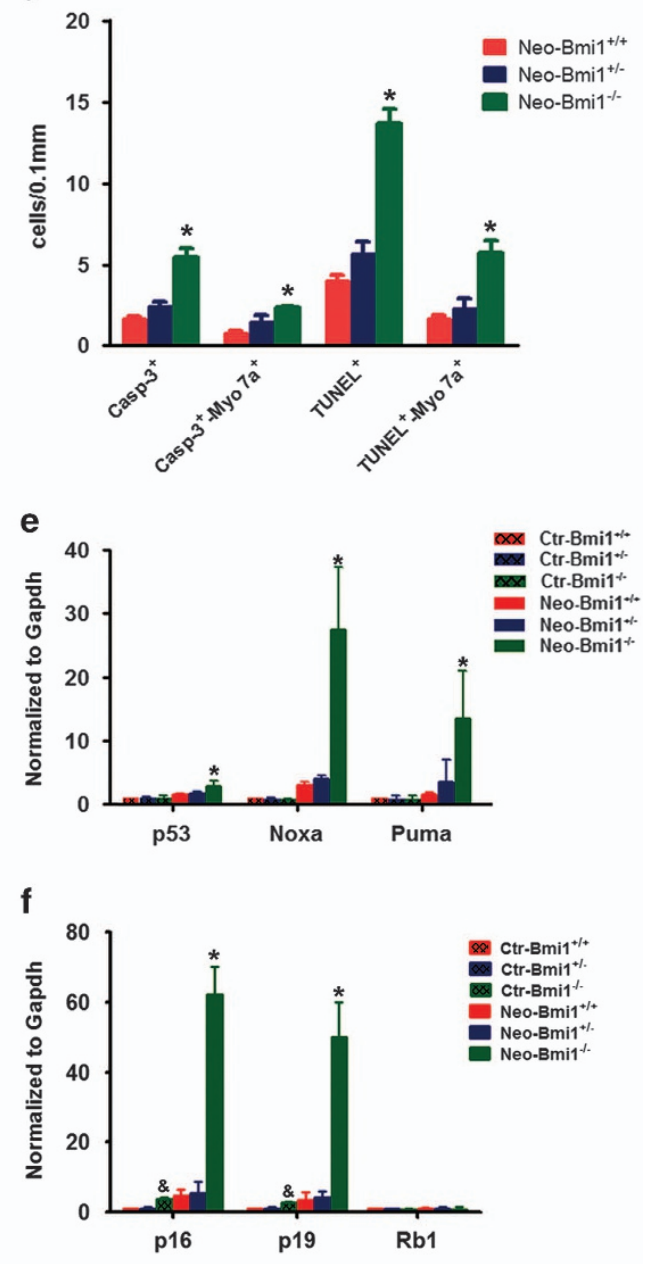

g

Neo-Bmi1 $^{+/+}$Neo-Bmi1 ${ }^{+/ \cdot}$ Neo-Bmi ${ }^{1 /}$ p53

GAPDH 
The plenty of mitochondria and high oxygen consumption in mouse auditory hair cells make them sensitive to oxidative stress especially challenged by external stimulation such as noise and ototoxic drugs. ${ }^{9}$ It has been reported that Bmi1deficient thymocytes ${ }^{13}$ and neurons ${ }^{42}$ have an increased level of intracellular ROS due to deregulated expression of genes related to mitochondrial function and ROS generation. In our study, we reported severe ototoxic drug-induced hair cell damage (Figure 3) accompanied with higher levels of free radicals and mitochondrial ROS accumulation (Figure 5) in $\mathrm{Bmi}^{-1-}$ hair cells after neomycin injury, which suggested ROS involved in the increased injury sensitivity to aminoglycosides in $\mathrm{Bmi}^{-1-}$ cochlea. After antioxidant NAC treatment, the number of survived hair cells in $\mathrm{Bmi}^{-1-}$ mice had no significant difference compared with WT mice (Figure 6). This finding demonstrated that the high ROS level was the major cause of the high injury sensitivity to ototoxic drugs in $\mathrm{Bmi}^{-/}$ cochlea, and indicated that Bmi1 regulates the hair cell survival by controlling the levels of ROS.

Balance between prooxidant and antioxidant molecules is critical to determine the rate of oxidative damage accumulation. When external stimulation brings out accumulation of ROS, the expression of antioxidant response genes also increased. In this study, we first reported the injury-induced dramatic increase of oxidizing enzymes (Alox15 and Lpo) and antioxidant genes (xCT, Nqo1 and Sod2) in mouse cochlea (Figure 5). Previous studies have reported the increased expression of oxidizing enzymes in $B \mathrm{Bmi}^{-/-}$thymocytes ${ }^{13}$ and decreased expression of antioxidant enzymes in $\mathrm{Bmi}^{-/-}$neurons. ${ }^{42}$ In $\mathrm{Bmi}^{-/-}$ cochlea, the increment amplitude of oxidizing enzymes increased, while the increment amplitude of antioxidant genes decreased compared with WT control after neomycin injury (Figure 6), indicating that aggravated disequilibrium of antioxidant-prooxidant balance is responsible to the increased accumulation of ROS. These results suggested that Bmi1 controls the antioxidant-prooxidant balance to maintain redox homeostasis in mouse auditory hair cells.

Several pathways are involved in Bmi1 deficiency-induced cell death, including the following: (1) Bmi1 deficiency leads to mitochondrial dysfunction resulting in increased levels of intracellular ROS and subsequent engagement of the DDR pathway in which Chk2 and p53 were activated; ${ }^{13}$ (2) Bmi1 deficiency directly leads to p53-mediated repression of antioxidant genes, resulting in increased ROS; ${ }^{41}$ (3) Bmi1 deficiency deregulates the expression of $p 19$, resulting in phosphorylation of $\mathrm{p} 53$, which triggers $\mathrm{p} 53$-dependent apoptosis; ${ }^{28}$ (4) Bmi1 deficiency also can directly deregulate the expression of Noxa (also known as Pmaip1, phorbol-12myristate-13-acetate-induced protein 1) independent of p19 and p53 (Yamashita et al. ${ }^{38}$ ). In the absence of neomycin injury, the expression of p16 and p19 had already significantly increased in cultured neonatal $\mathrm{Bmi}^{-/-}$cochlea, although there was no significant hair cell loss in neonatal $\mathrm{Bmi} 1^{-/-}$ cochlea (Figure 4). After neomycin treatment, significantly more hair cell loss was observed in $B \mathrm{Bmi}^{-1-}$ cochlea when compared with WT control (Figure 3), and this was accompanied by significantly higher levels of free radicals and mitochondrial ROS (Figure 5), more DNA damage-induced $\mathrm{yH} 2 \mathrm{AX}$ foci (Figure 4), as well as higher expression levels of p16, p19, p53 and p53 target genes (noxa and puma) in $\mathrm{Bmi}^{-1^{-1}}$ cochlea than in WT control (Figure 4). ROS can oxidize cell constituents, such as DNA, lead to DNA damage and activate multiple apoptosis pathways including p53-dependent apoptosis. ${ }^{48-50}$ $\mathrm{H} 2 \mathrm{AX}$ triggers Chk2 signaling pathway and p53 activation. In cooperation with $\gamma \mathrm{H} 2 \mathrm{AX}$, p53 repairs DNA damage or induces cell death. ${ }^{51}$ In our study, we found that the peak of free radicals and mitochondrial ROS level was $2 \mathrm{~h}$ after neomycin treatment, whereas the peak of the expression of p53, noxa and puma were $12 \mathrm{~h}$ after neomycin treatment; thus, we speculated that Bmi1 deficiency led to the disequilibrium of antioxidantprooxidant balance, resulting in increased accumulation of ROS, which then triggered DNA damage and multiple apoptotic pathways including p53-dependent apoptosis.

NAC, an essential precursor to many endogenous antioxidants involved in the decomposition of peroxides, attenuates oxidative stress by replenishing intracellular GSH stores. ${ }^{52}$ In clinical trials, NAC improves lung function in patients with chronic obstructive pulmonary disease, highlighting the potential benefit of ROS-directed therapy. ${ }^{53}$ In the current study, both in vivo and in vitro results confirmed that NAC treatment ameliorated neomycin-induced hair cell damage, suggesting that antioxidant treatment might be an effective therapy for hearing loss induced by ototoxic drugs. Furthermore, we demonstrated that the increased sensitivity to ototoxic drugs caused by Bmi-1 deficiency was largely rescued by antioxidant treatment, indicating that Bmi1 regulated hair cell survival and sensitivity to ototoxic drugs by maintaining redox balance.

In summary, we first reported the expression pattern of Bmi1 in mouse cochlea and then demonstrated that $\mathrm{Bmi1}$ has an important role in the hair cell survival and regulates the sensitivity of hair cells to ototoxic drug via controlling redox balance. Lastly, we approved that ROS accumulation was the main reason for increased aminoglycoside sensitivity in $\mathrm{Bmi}^{-1-}$ hair cells, both in vitro and in vivo, via the antioxidant NAC rescue experiments. Our findings may provide new therapeutic targets for prevention of the hair cell death.

\section{Materials and Methods \\ Mice and genotyping. Bmi1 ${ }^{1 /-}$ mice (1290la/FVB/N hybrid background) that were backcrossed 10-12 times onto a C57BL/6J background were mated to generate $\mathrm{Bmi1}^{-1-}, \mathrm{Bmi1}^{+/-}$and WT mice (littermates) genotyped by PCR, as described previously. ${ }^{27}$ This study was carried out in strict accordance with the 'Guiding Directive for Humane treatment of Laboratory Animals' issued by the}

Figure 4 Apoptosis and DNA damage in hair cells was augmented in Bmi $1^{-1}$ - cochlear epithelium after neomycin insult. (a) Cleaved caspase-3 and myosin $7 a$ double staining in $\mathrm{Bmi}^{-1}, \mathrm{Bmi}^{+/-}$and Bmi $1^{+/+}$cultured cochlear epithelium after neomycin treatment for $8 \mathrm{~h}$. Middle turn. (b) TUNEL and myosin $7 \mathrm{a}$ double staining in Bmi $1^{-/-}$, $\mathrm{Bmi}^{+/-}$and Bmi1 ${ }^{+/+}$cultured cochlear epithelium after neomycin treatment for $8 \mathrm{~h}$. Middle turn. (c) $\gamma \mathrm{H} 2 \mathrm{AX}$ and myosin $7 \mathrm{a}$ double staining in Bmi $1^{-/-}$, Bmi ${ }^{+/}-$and Bmi $1^{+/+}$ cultured cochlear epithelium after neomycin treatment for $8 \mathrm{~h}$. Middle turn. (d) Statistical data revealed that the number of cleaved caspase- $3^{+} / \mathrm{myosin} 7 \mathrm{a}^{+}$and $\mathrm{TUNEL}+\mathrm{myosin}$ $7 \mathrm{a}^{+}$cells significantly increased in Bmi1 ${ }^{-/-}$hair cells when compared with WT controls. (e and f) Real-time RT-PCR data showed the mRNA levels of p53, Noxa, Puma, p19, p16 and $\mathrm{Rb} 1$ after neomycin damage for $12 \mathrm{~h}$. (g) Western blotting results showed the protein levels of p53 increased in Bmi $1^{-I-}$ cochlear epithelium after neomycin damage for $12 \mathrm{~h}$. Scale bars: $20 \mu \mathrm{m} .{ }^{*} P<0.05$ versus Neo-Bmi $1^{+/+}$group. ${ }^{\&} P<0.05$ versus $\mathrm{Ctr}-\mathrm{Bmi} 1^{+/+}$group. $n=5$ for each group 
a
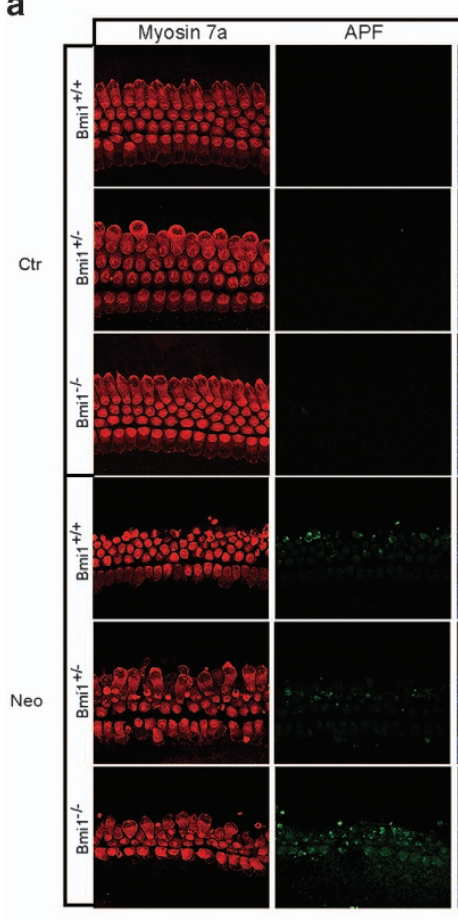

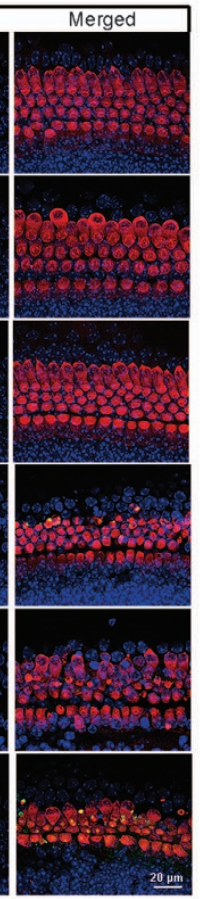

b

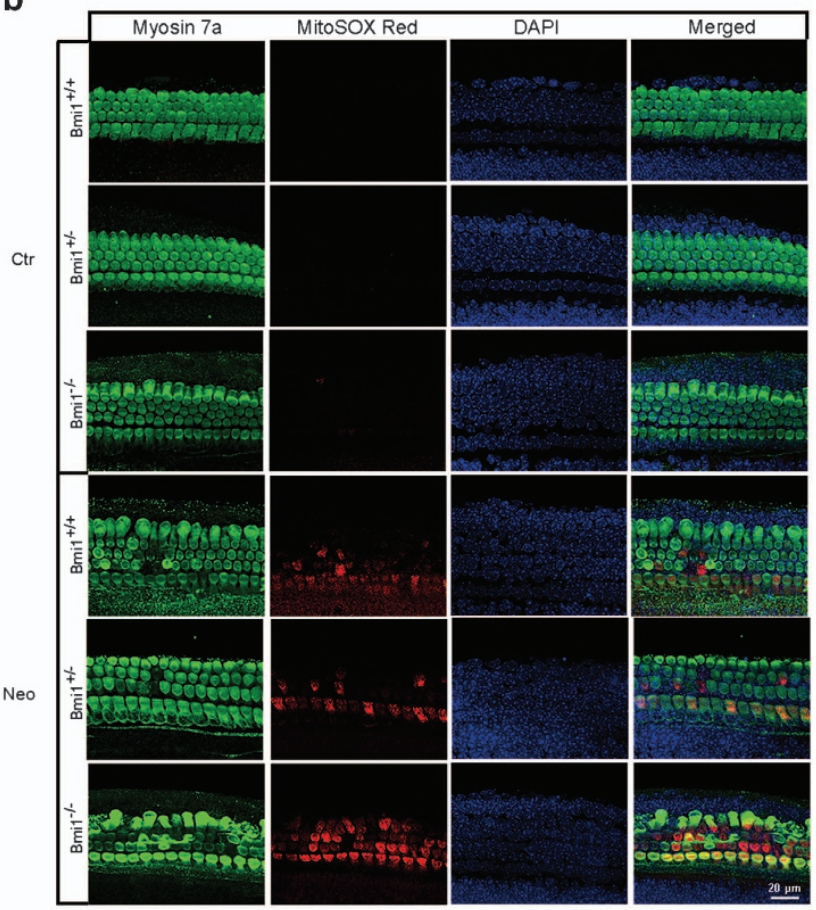

C

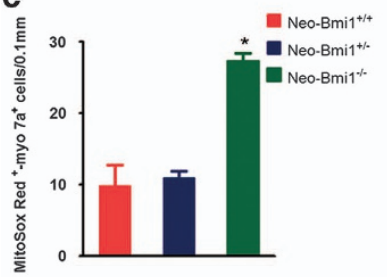

d

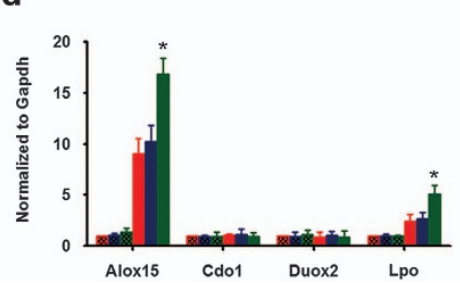

e

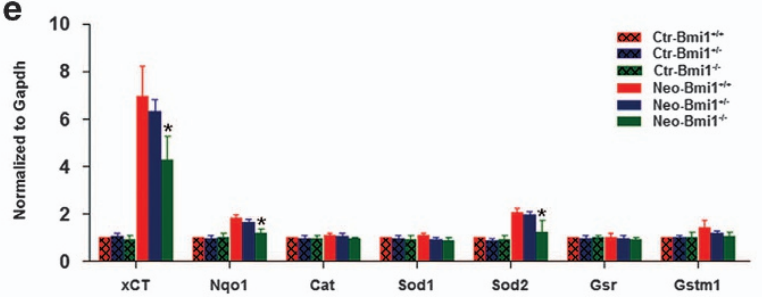

Figure 5 The level of ROS increased and the disequilibrium of antioxidant-prooxidant balance deteriorated in Bmi $1^{-1-}$ hair cells after neomycin insult. (a) In the absence of damage, APF fluorescence in cochlear epithelium could not be detected. Two hours after $0.25 \mathrm{mM}$ neomycin treatment, APF fluorescence is obviously stronger in hair cells of $\mathrm{Bmi1}^{-1-}$ mice compared with that in WT and Bmi1 ${ }^{+/}$mice. Middle turn. (b) In the absence of damage, MitoSox Red fluorescence in cochlear epithelium could not be detected. Two hours after $0.25 \mathrm{mM}$ neomycin treatment, MitoSox Red fluorescence is obviously stronger in hair cells of Bmi $1^{-1}-$ mice, compared with that in WTand Bmi1 ${ }^{+/-}$mice. Middle turn. (c) Statistical data revealed that the number of MitoSox Red $/$ myosin $7 \mathrm{a}^{+}$cells significantly increased in Bmi $1^{-1-}$ hair cells when compared with WT controls. Quantitative data showed the expression level of antioxidant genes (d) and oxidases (e) at $2 \mathrm{~h}$ after neomycin treatment. Scale bars: $20 \mu \mathrm{m}$. ${ }^{*} P<0.05$ versus Neo-Bmi1 ${ }^{+/+}$group. $n=5$ for each group

Chinese National Ministry of Science and Technology on September, 2006. All experiments were approved by the Shanghai Medical Experimental Animal Administrative Committee (Permit Number: 2009-0082). All efforts were made to minimize suffering and reduce the number of animals used.

Experimental protocol (in vivo studies). To explore the effect of Bmi1 deficiency on injury sensitivity to ototoxic drug in cochlear hair cells, neomycin was injected subcutaneously once daily for 5 days from postnatal day 7 (P7) at a final dose of $125 \mathrm{mg} / \mathrm{kg} / \mathrm{day}$. After exposure to neomycin, the hearing threshold was evaluated by ABR measurement at P22. For NAC rescue experiment, NAC ( $200 \mathrm{mg} / \mathrm{kg} / \mathrm{day}$, i.p.) were injected for 7 days at the beginning of neomycin insult. Next, mice of either sex were killed and cochleae were fixed in $4 \%$ paraformaldehyde (PFA). After decalcification, cochlear epithelium was prepared for morphological analysis.

ABR and DPOAE measurement. $A B R$ analysis was performed in anesthetized P22 and P30 mice, to measure the hearing threshold, as described previously. ${ }^{54}$ The hearing threshold of P22 and P30 mice was assessed at four frequencies $(8,16,24$ and $32 \mathrm{kHz}$ ) in a TDT system 3 (Tucker-Davies Technologies, Gainesville, FL, USA). DPOAE signal was measured with a TDT-RZ6 system (Tucker-Davis Technologies). The stimuli for eliciting DPOAEs were two sine wave tones of differing frequencies $(F 2=1.2 F 1)$ of $1 \mathrm{~s}$ duration with $\mathrm{F} 2$ ranging from 4 to $40 \mathrm{kHz}$. The two tones were presented at identical intensities, which ranged from $20-90 \mathrm{~dB}$ SPL in $10 \mathrm{~dB}$ increments. The acoustic signal picked up by the microphone in the earbar was digitized at $200 \mathrm{kHz}$ and the magnitude of the $2 \mathrm{~F} 1-\mathrm{F} 2$ distortion product determined by FFT. The surrounding noise floor was also calculated by averaging 20 adjacent frequency bins around the distortion product frequency. DPOAE thresholds were calculated offline by interpolating the data and identifying when the signal was greater than $-5 \mathrm{~dB} S P L$ and greater than two S.D. above the noise floor. If no DPOAE response was detected even at our equipment limits of $90 \mathrm{~dB}$ SPL, we arbitrarily defined the threshold to be $90 \mathrm{~dB}$.

Experimental protocol (in vitro studies). Cochlear sensory epithelium was dissected from P0 mice and cultured as previously reported. ${ }^{55}$ Neomycin (0.25 mM, Sigma-Aldrich, St. Louis, MO, USA) or cisplatin (10 $\mu \mathrm{M}$, SigmaAldrich) was added for $24 \mathrm{~h}$ to kill hair cells. After neomycin or cisplatin was removed, the tissues were cultured in serum-free medium for additional $48 \mathrm{~h}$. For NAC rescue experiment, NAC $(20 \mathrm{mM})$ were added in medium for $48 \mathrm{~h}$ at the beginning of neomycin insult.

Immunofluorescence, phalloidin, TUNEL and APF staining. Mouse monoclonal anti-Bmi1 (Millipore, 1:500), rabbit polyclonal anti-cleaved 
a

in vitro study

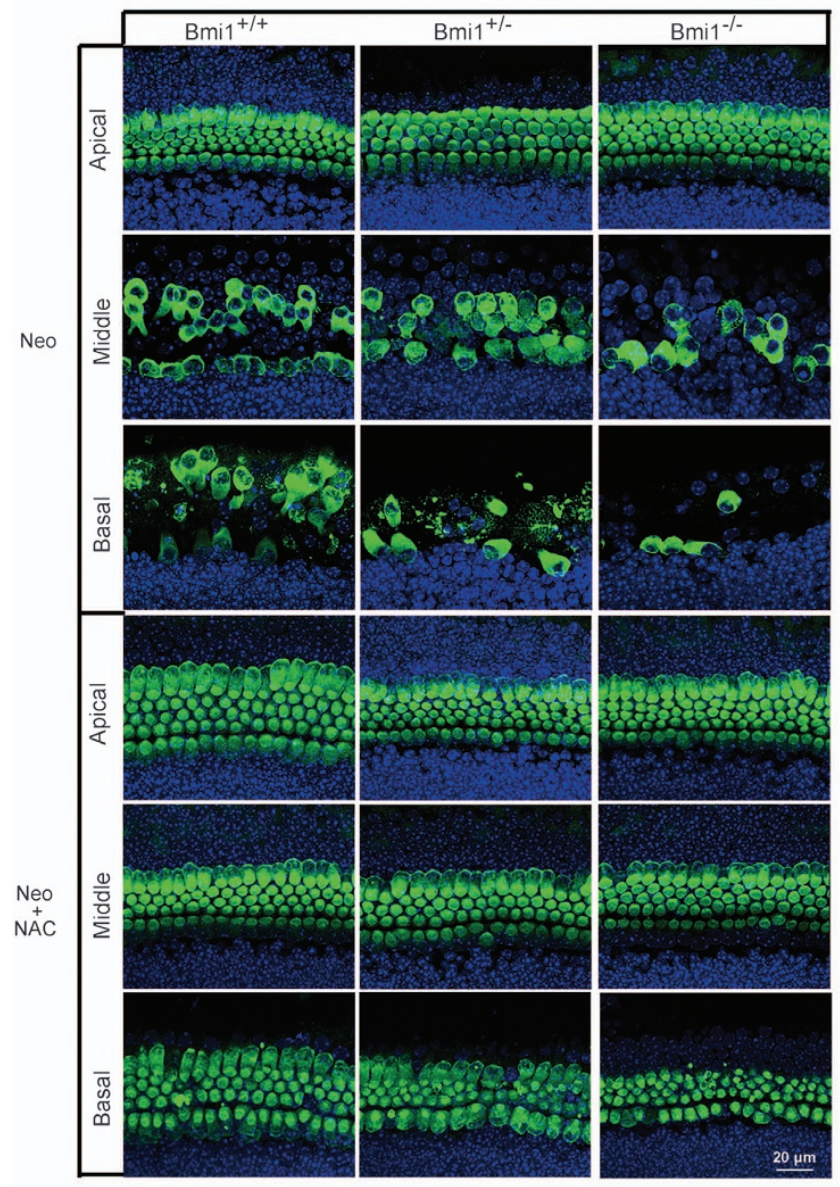

b

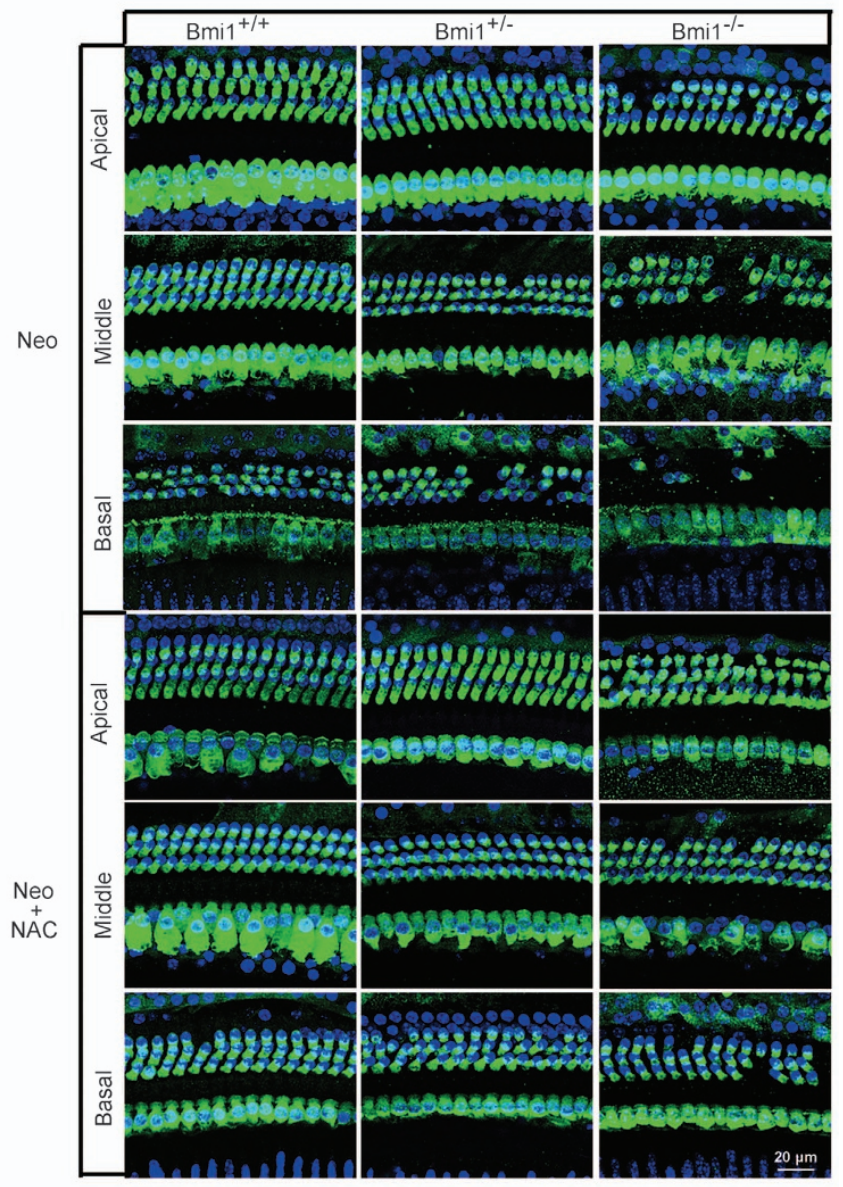

C

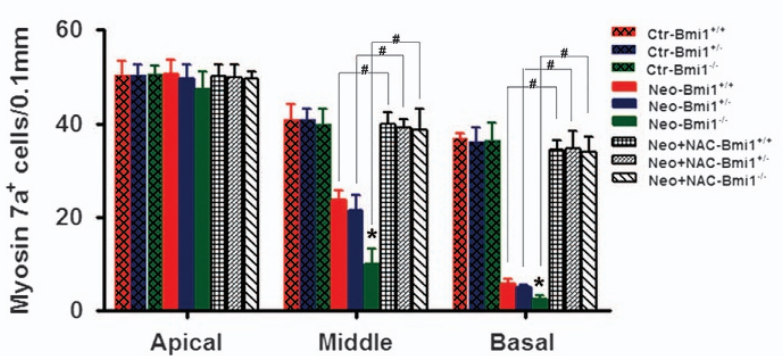

d

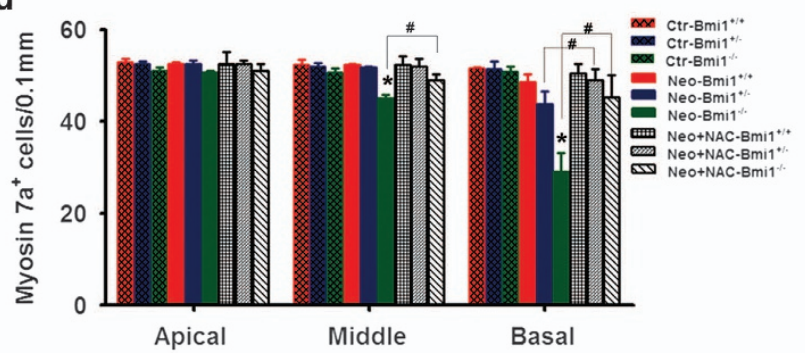

Figure 6 Antioxidant treatment rescued Bmi1 ${ }^{-/-}$hair cells. (a) In vitro study showed that NAC treatment rescued Bmi1 ${ }^{-/-}$hair cells from neomycin injury. (b) In vivo study showed that neomycin induced hair cells loss attenuated in Bmi $1^{-1-}$ cochlea after neomycin treatment. (c and $\left.\mathbf{d}\right)$ Statistical data of survival hair cells after neomycin and NAC treatment. Scale bars: $20 \mu \mathrm{m} .{ }^{*} P<0.05$ versus Neo-Bmi1 ${ }^{+/+}$group; ${ }^{\#} P<0.05 . n=5$ for each group

caspase-3 (s9661, Cell Signaling Technology Inc, Danvers, MA, USA), polyclonal anti-myosin VIIA (Myo7a, 1:1000) (Proteus Biosciences, Ramona, CA, USA), polyclonal anti- $\gamma \mathrm{H} 2 \mathrm{AX}$ (Abcam, Cambridge, UK; $1: 200$ ), goat polyclonal anti-SR $\gamma$ (sex-determining region $\gamma$ )-box 2 (Sox2) (sc-17320, Santa Cruz Biotechnology, Dallas, TX, USA) and phalloidin-tetramethylrhodamine (TRITC) (Sigma-Aldrich, $1: 1000)$ were used. Briefly, nonspecific binding sites were blocked for $1 \mathrm{~h}$ in $0.3 \%$ Triton X-100 and 10\% (v/v) heat-inactivated normal serum in PBS (PBT1). Tissues were then incubated overnight at $4{ }^{\circ} \mathrm{C}$ in PBT1 with primary antibodies. After unbound antibodies were removed, tissues were incubated with the corresponding secondary antibodies conjugated with TRITC, fluorescein isothiocyanate or Cy5 (Jackson ImmunoResearch, West Grove, PA, USA). Counterstaining with DAPI (Sigma-Aldrich) allowed visualization of the cell nuclei. Specimens were examined by confocal fluorescence microscopy (Leica SP5, Heidelberg, Germany). Negative control experiments were performed as above by omitting the primary antibodies.

TUNEL Kit (Roche, Indianapolis, IN, USA) was used to detect apoptotic cells, according to the instructions of the manufacturer. APF staining was performed to detect hROS as previous reported. ${ }^{45}$ After being exposed in $0.25 \mathrm{mM}$ neomycin, the explants were rinsed with HBSS and stained with APF ( $12.5 \mu \mathrm{M}$, Cell Technology Inc., Beverly, MA, USA) for 30 min at $37^{\circ} \mathrm{C}$ in humidified air with $5 \% \mathrm{CO}_{2}$. APF is minimally fluorescent; however, when reacted with $\mathrm{hROS}(\bullet \mathrm{OH}, \mathrm{ONOO}-$ and $-\mathrm{OCl})$, they are converted to fluorescein and exhibit strong, dose-dependent fluorescence. MitoSOX Red (Invitrogen, Carlsbad, CA, USA) was used to detect mitochondrial ROS. After being exposed in $0.25 \mathrm{mM}$ neomycin, the explants were washed with PBS and stained with MitoSOX Red probe (Invitrogen, $5 \mu \mathrm{M}$ ), incubated for $10 \mathrm{~min}$. After staining, the cells were fixed in PFA. 
Real-time PCR. Two micrograms of total RNA were used for reverse transcription with Superscript III reverse transcriptase (Invitrogen). Real-time PCR was performed on $A B I 7500$ real-time PCR system (Applied Biosystems, Foster City, CA, USA) using GoTaq qPCR Master Mix (Promega, Madison, WI, USA). All primers were designed to flank individual exons and tested by PCR. The optimized conditions were held constant for each sample to assure valid comparison of the results. Primers sets used were as follows: GAPDH(F) 5'-TGCGACTTCAA CAGCAACTC-3'; (R) 5'-CTTGCTCAGTGTCCTTGCTG-3', p16(F) 5'-CAACGC CCCGAACTCTTTC-3'; (R) 5'-ATCTGCACCGTAGTTGAGCA-3', p19(F) 5'-TGTT GTTGAGGCTAGAGAGGA-3'; (R) 5'-CGAATCTGCACCGTAGTTGA-3', p53(F) 5'-CATCCTCCTCCTTCCCAGC-3'; (R) 5'-CAGTGAGGTGATGGCAGGAT-3', Rb1 (F) 5'-AAGTTCTCACCTCCTGCACT-3'; (R) 5'-CTCTTCTGGGTGTTCGAGGT-3', Noxa(Pmaip1)(F) 5'-AGTCGCAAAAGAGCAGGATG-3'; (R) 5'-AAGCTTTGGA AGAACTCAGGT-3', Puma(also known as Bbc3, BCL2-binding component 3)(F) 5'-GTGTGGAGGAGGAGGAGTG-3'; (R) 5'-CTGGGTAAGGGGAGGAGTC-3', superoxide dismutase 1, soluble (Sod1) (F) 5'-GGGTTCCACGTCCATCAGTA-3'; (R) 5'-GGTCTCCAACATGCCTCTCT-3', Sod2(F) 5'-TGTTACAACTCAGGTCG CTCT-3'; (R) 5'-CTCCCACAGACACGGCTG-3', xCT(F) 5'-TGGAGGTCTTTGGTC CTTTG-3'; (R) 5'-CCAGGATGTAGCGTCCAAAT-3', catalase(F) 5'-AGCGGAT TCCTGAGAGAGTG-3'; (R) 5'-GACTGTGGAGAATCGAACGG-3', glutathione S-transferase, mu 1 (Gstm1) (F) 5'-TCCTGCCCACGTTTCTCTAG-3'; (R) 5'-AGTCTGTGTATTCCAGGAGCA-3', Nq01(F) 5'-ACTTCAACCCCATCATTT CCAG-3'; (R) 5'-TATCACCAGGTCTGCAGCTT-3', glutathione reductase (Gsr)

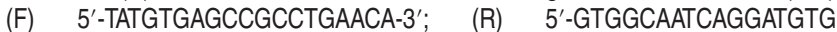
TGG-3', Alox15(F) 5'-GACTTGGCTGAGCGAGGACT-3'; (R) 5'-CTTGACACCAG CTCTGCA-3', Duox2(F) 5'-CCATCCTCAAAGACCTGGTCTTCA-3'; (R) 5'-CTCAG CCAGCTGAGTAATGTAGATGT-3', Lpo(F) 5'-CTGGACCAGAAGAGATCCATG-3'; (R) 5'-TCACCAGGTGGGAACATGATGG-3', Cdo1(F) 5'-GTGGATCAAGGAAATG GGA-3'; (R) 5'-CTTGATCATCTCGTTGGA-3'.

Western blotting. Total protein was isolated using the AllPrep DNA/RNA/ Protein Mini Kit (Qiagen, Valencia, CA, USA). Proteins were separated by $12 \%$ SDS-PAGE. After electrophoresis, the proteins were transferred to PVDF membranes (Millipore). The membranes were blocked with $5 \%$ non-fat dried milk in TBST for $1 \mathrm{~h}$ at room temperature. The primary antibodies, including anti-p53 antibody (Abcam, dilution 1: 1000) and anti-GAPDH antibody (Cell Signaling Technology Inc., dilution 1: 1000), were added into the blocking buffer overnight at $4^{\circ} \mathrm{C}$. After rinsing three times ( $10 \mathrm{~min}$ each) with TBST, the membranes were incubated with HRP-conjugated secondary antibody at a concentration of 1:5000 (Supersignal West, Pierce, Rockford, IL, USA) for $1 \mathrm{~h}$ at room temperature. The immunoreactive bands were visualized using an ECL kit (Pierce).

Cell counting and statistical analysis. To quantify the immunostaining positive cells, the entire cochlea was divided into nine segments of equal length from the apex to the base. Data are presented as the mean \pm S.D. ANOVA and Bonferroni's multiple comparison test were used to analyze the differences, and differences between groups were considered significant when $P<0.05$.

\section{Conflict of Interest}

The authors declare no conflict of interest.

Acknowledgements. This work was supported by grants from the Major State Basic Research Development Program of China (973 Program) (2011CB504506 and 2015CB965000), the National Natural Science Foundation of China (81230019, $81470687,81100709,81300825,81371094$ and 81470692), the Innovation Programme of Major Basic Research Projects, the Science and Technology Commission of Shanghai Municipality (14DJ1400203), Shanghai Rising-Star Program (12QA1400500), Jiangsu Province Natural Science Foundation (BK20140620) and the Fundamental Research Funds for the Central Universities (2242014R30022 and NO2013WSN085), the Construction Program of Shanghai Committee of Science and Technology (12DZ2251700), the Major Program of Shanghai Committee of Science and Technology (11441901000). We thank Wen Li, Chuijin Lai, Luo Guo and Tianfeng Wang for their excellent technique support; Jin Li and Yalin Huang (IBS, Fudan University) for help with the confocal microscope.

\section{Author contributions}

$\mathrm{HL}$ conceived and designed the experiments. YC, HL, YZ, SS and WN performed the experiments. $\mathrm{YC}, \mathrm{DM}$ and $\mathrm{HL}$ analyzed the data. $\mathrm{HL}, \mathrm{YC}$ and $\mathrm{RC}$ wrote the paper.
1. Xiang M, Gao WQ, Hasson T, Shin JJ. Requirement for Brn-3c in maturation and survival, but not in fate determination of inner ear hair cells. Development 1998; 125: 3935-3946.

2. Li S, Price SM, Cahill H, Ryugo DK, Shen MM, Xiang M. Hearing loss caused by progressive degeneration of cochlear hair cells in mice deficient for the Barhl1 homeobox gene. Development 2002; 129: 3523-3532.

3. Wallis D, Hamblen M, Zhou Y, Venken KJ, Schumacher A, Grimes HL et al. The zinc finger transcription factor Gfi1, implicated in lymphomagenesis, is required for inner ear hair cell differentiation and survival. Development 2003; 130: 221-232.

4. Sage C, Huang M, Vollrath MA, Brown MC, Hinds PW, Corey DP et al. Essential role of retinoblastoma protein in mammalian hair cell development and hearing. Proc Natl Acad Sci USA 2006; 103: 7345-7350.

5. Fasquelle L, Scott HS, Lenoir M, Wang J, Rebillard G, Gaboyard S et al. Tmprss3, a transmembrane serine protease deficient in human DFNB8/10 deafness, is critical for cochlear hair cell survival at the onset of hearing. J Biol Chem 2011; 286: 17383-17397.

6. Kozlowski DJ, Whitfield TT, Hukriede NA, Lam WK, Weinberg ES. The zebrafish dog-eared mutation disrupts eya1, a gene required for cell survival and differentiation in the inner ear and lateral line. Dev Biol 2005; 277: 27-41.

7. Foller M, Jaumann M, Dettling J, Saxena A, Pakladok T, Munoz C et al. AMP-activated protein kinase in BK-channel regulation and protection against hearing loss following acoustic overstimulation. FASEB J 2012; 26: 4243-4253.

8. Clough RL, Sud R, Davis-Silberman N, Hertzano R, Avraham KB, Holley M et al. Brn-3c (POU4F3) regulates BDNF and NT-3 promoter activity. Biochem Biophys Res Commun 2004; 324: 372-381.

9. Huang T, Cheng AG, Stupak H, Liu W, Kim A, Staecker $\mathrm{H}$ et al. Oxidative stress-induced apoptosis of cochlear sensory cells: otoprotective strategies. Int J Dev Neurosci 2000; 18: 259-270.

10. Wang X, Martindale JL, Liu Y, Holbrook NJ. The cellular response to oxidative stress: influences of mitogen-activated protein kinase signalling pathways on cell survival. Biochem J 1998; 333 (Pt 2): 291-300.

11. Kannan K, Jain SK. Oxidative stress and apoptosis. Pathophysiology 2000; 7: 153-163.

12. Chandra J, Samali A, Orrenius S. Triggering and modulation of apoptosis by oxidative stress. Free Radic Biol Med 2000; 29: 323-333.

13. Liu J, Cao L, Chen J, Song S, Lee IH, Quijano C et al. Bmi1 regulates mitochondrial function and the DNA damage response pathway. Nature 2009; 459: 387-392.

14. Petrosillo G, Ruggiero FM, Pistolese M, Paradies G. Ca2+-induced reactive oxygen species production promotes cytochrome $\mathrm{c}$ release from rat liver mitochondria via mitochondrial permeability transition (MPT)-dependent and MPT-independent mechanisms: role of cardiolipin. J Biol Chem 2004; 279: 53103-53108.

15. Petrosillo $G$, Ruggiero FM, Paradies $G$. Role of reactive oxygen species and cardiolipin in the release of cytochrome c from mitochondria. FASEB J 2003; 17: 2202-2208.

16. Tian CJ, Kim YJ, Kim SW, Lim HJ, Kim YS, Choung YH. A combination of cilostazol and Ginkgo biloba extract protects against cisplatin-induced Cochleo-vestibular dysfunction by inhibiting the mitochondrial apoptotic and ERK pathways. Cell Death Dis 2013; 4: e509.

17. Sha SH, Schacht J. Formation of reactive oxygen species following bioactivation of gentamicin. Free Radic Biol Med 1999; 26: 341-347.

18. Kim HJ, Lee JH, Kim SJ, Oh GS, Moon HD, Kwon KB et al. Roles of NADPH oxidases in cisplatininduced reactive oxygen species generation and ototoxicity. J Neurosci 2010; 30: 3933-3946.

19. Bottger EC, Schacht J. The mitochondrion: a perpetrator of acquired hearing loss. Hear Res 2013; 303: 12-19.

20. Sha SH, Schacht J. Antioxidants attenuate gentamicin-induced free radical formation in vitro and ototoxicity in vivo: D-methionine is a potential protectant. Hear Res 2000; 142: 34-40.

21. Kim SJ, Park C, Han AL, Youn MJ, Lee JH, Kim Y et al. Ebselen attenuates cisplatin-induced ROS generation through Nrf2 activation in auditory cells. Hear Res 2009; 251: 70-82.

22. Ding D, Qi W, Yu D, Jiang H, Han C, Kim MJ et al. Addition of exogenous NAD+ prevents mefloquine-induced neuroaxonal and hair cell degeneration through reduction of caspase-3mediated apoptosis in cochlear organotypic cultures. PLoS One 2013; 8: e79817.

23. Kawamoto K, Sha SH, Minoda R, Izumikawa M, Kuriyama H, Schacht J et al. Antioxidant gene therapy can protect hearing and hair cells from ototoxicity. Mol Ther 2004; 9: 173-181.

24. Golbabapour S, Majid NA, Hassandarvish P, Hajrezaie M, Abdulla MA, Hadi AH. Gene silencing and Polycomb group proteins: an overview of their structure, mechanisms and phylogenetics. OMICS 2013; 17: 283-296.

25. Simon JA, Kingston RE. Mechanisms of polycomb gene silencing: knowns and unknowns. Nat Rev Mol Cell Biol 2009; 10: 697-708.

26. Yu M, Mazor T, Huang H, Huang HT, Kathrein KL, Woo AJ et al. Direct recruitment of polycomb repressive complex 1 to chromatin by core binding transcription factors. Mol Cell 2012; 45: 330-343.

27. Lessard J, Sauvageau G. Bmi-1 determines the proliferative capacity of normal and leukaemic stem cells. Nature 2003; 423: 255-260.

28. Park IK, Qian D, Kiel M, Becker MW, Pihalja M, Weissman IL et al. Bmi-1 is required for maintenance of adult self-renewing haematopoietic stem cells. Nature 2003; 423: 302-305.

29. Bruggeman SW, Hulsman D, Tanger E, Buckle T, Blom M, Zevenhoven J et al. Bmi1 controls tumor development in an Ink4a/Arf-independent manner in a mouse model for glioma. Cancer Cell 2007; 12: 328-341.

30. Park IK, Morrison SJ, Clarke MF. Bmi1, stem cells, and senescence regulation. J Clin Invest 2004; 113: 175-179.

31. Yang MH, Hsu DS, Wang HW, Wang HJ, Lan HY, Yang WH et al. Bmi1 is essential in Twist1induced epithelial-mesenchymal transition. Nat Cell Biol 2010; 12: 982-992. 
32. Biehs B, Hu JK, Strauli NB, Sangiorgi E, Jung H, Heber RP et al. BMl1 represses Ink4a/Arf and Hox genes to regulate stem cells in the rodent incisor. Nat Cell Biol 2013; 15: 846-852.

33. Lukacs RU, Memarzadeh S, Wu H, Witte ON. Bmi-1 is a crucial regulator of prostate stem cell self-renewal and malignant transformation. Cell Stem Cell 2010; 7: 682-693.

34. Molofsky AV, Pardal R, Iwashita T, Park IK, Clarke MF, Morrison SJ. Bmi-1 dependence distinguishes neural stem cell self-renewal from progenitor proliferation. Nature 2003; 425 : 962-967.

35. Fasano CA, Dimos JT, Ivanova NB, Lowry N, Lemischka IR, Temple S. shRNA knockdown of Bmi-1 reveals a critical role for p21-Rb pathway in NSC self-renewal during development. Cell Stem Cell 2007; 1: 87-99.

36. Jacobs JJ, Kieboom K, Marino S, DePinho RA, van Lohuizen M. The oncogene and Polycomb-group gene bmi-1 regulates cell proliferation and senescence through the ink4a locus. Nature 1999; 397: 164-168.

37. Rizo A, Olthof S, Han L, Vellenga E, de Haan G, Schuringa JJ. Repression of BMl1 in norma and leukemic human CD34(+) cells impairs self-renewal and induces apoptosis. Blood 2009; 114: $1498-1505$

38. Yamashita M, Kuwahara M, Suzuki A, Hirahara K, Shinnaksu R, Hosokawa $\mathrm{H}$ et al. Bmi1 regulates memory CD4 T cell survival via repression of the Noxa gene. J Exper Med 2008; 205: $1109-1120$

39. Nakamura S, Oshima M, Yuan J, Saraya A, Miyagi S, Konuma T et al. Bmi1 confers resistance to oxidative stress on hematopoietic stem cells. PLoS One 2012; 7: e36209.

40. Dong Q, Oh JE, Chen W, Kim R, Kim RH, Shin KH et al. Radioprotective effects of Bmi-1 involve epigenetic silencing of oxidase genes and enhanced DNA repair in normal human keratinocytes. J Invest Dermatol 2011; 131: 1216-1225.

41. Abdouh M, Chatoo W, El Haijar J, David J, Ferreira J, Bernier G. Bmi1 is down-regulated in the aging brain and displays antioxidant and protective activities in neurons. PLOS One 2012; 7: e31870.

42. Chatoo W, Abdouh M, David J, Champagne MP, Ferreira J, Rodier F et al. The polycomb group gene Bmi1 regulates antioxidant defenses in neurons by repressing p53 pro-oxidant activity. J Neurosci 2009; 29: 529-542.

43. Matsui Jl, Ogilvie JM, Warchol ME. Inhibition of caspases prevents ototoxic and ongoing hair cell death. J Neurosci 2002; 22: 1218-1227.

44. Yuan J, Adamski R, Chen J. Focus on histone variant $\mathrm{H} 2 \mathrm{AX}$ : to be or not to be. FEBS Lett 2010; 584: 3717-3724.

45. Choung YH, Taura A, Pak K, Choi SJ, Masuda M, Ryan AF. Generation of highly-reactive oxygen species is closely related to hair cell damage in rat organ of Corti treated with gentamicin. Neuroscience 2009; 161: 214-226.
46. Du H, Guo L, Fang F, Chen D, Sosunov AA, McKhann GM et al. Cyclophilin D deficiency attenuates mitochondrial and neuronal perturbation and ameliorates learning and memory in Alzheimer's disease. Nat Med 2008; 14: 1097-1105.

47. Yousefi S, Mihalache C, Kozlowski E, Schmid I, Simon HU. Viable neutrophils release mitochondrial DNA to form neutrophil extracellular traps. Cell Death Differ 2009; 16: 1438-1444.

48. Cardaci S, Filomeni G, Rotilio G, Ciriolo MR. Reactive oxygen species mediate p53 activation and apoptosis induced by sodium nitroprusside in SH-SY5Y cells. Mol Pharmacol 2008; 74: 1234-1245.

49. Huang J, Wu L, Tashiro S, Onodera S, Ikejima T. Reactive oxygen species mediate oridonininduced HepG2 apoptosis through p53, MAPK, and mitochondrial signaling pathways. J Pharmacol Sci 2008; 107: 370-379.

50. Tsang WP, Chau SP, Kong SK, Fung KP, Kwok TT. Reactive oxygen species mediate doxorubicin induced p53-independent apoptosis. Life Sci 2003; 73: 2047-2058.

51. Rufini A, Tucci $P$, Celardo I, Melino G. Senescence and aging: the critical roles of p53. Oncogene 2013; 32: 5129-5143.

52. Small DM, Coombes JS, Bennett N, Johnson DW, Gobe GC. Oxidative stress, anti-oxidant therapies and chronic kidney disease. Nephrology (Carlton) 2012; 17: 311-321.

53. Demedts M, Behr J, Buhl R, Costabel U, Dekhuijzen R, Jansen HM et al. High-dose acetylcysteine in idiopathic pulmonary fibrosis. N Engl J Med 2005; 353: 2229-2242.

54. Yu H, Lin Q, Wang Y, He Y, Fu S, Jiang H et al. Inhibition of H3K9 methyltransferases G9a/ GLP prevents ototoxicity and ongoing hair cell death. Cell Death Dis 2013; 4: e506.

55. Chen Y, Yu H, Zhang Y, Li W, Lu N, Ni W et al. Cotransfection of Pax2 and Math1 promote in situ cochlear hair cell regeneration after neomycin insult. Sci Rep 2013; 3: 2996.

(1) Cell Death and Disease is an open-access journal published by Nature Publishing Group. This work is licensed under a Creative Commons Attribution 4.0 International Licence. The images or other third party material in this article are included in the article's Creative Commons licence, unless indicated otherwise in the credit line; if the material is not included under the Creative Commons licence, users will need to obtain permission from the licence holder to reproduce the material. To view a copy of this licence, visit http://creativecommons.org/licenses/by/4.0 